\title{
Identidad, autonarración y performatividad en La hija del Ganges de Asha Miró
}

Marina Bettaglio

La hija del Ganges (2003), by the Indian-Catalan writer Asha Miró, is an autobiographical text that reflects the typical anxieties of adoption narratives: the trauma of her abandonment, the loss of her family of origin, and her need to understand the circumstances of her own birth, above all to unearth the motives that compelled her biological parents to give her up. The textual construction of Miró's life story reveals the importance of the performative act in autobiographical writing as the «creation and re-creation of the self at the time of writing» (Laureiro 1). This article analyzes the process of identity construction in autobiographical writing in light of the narrative theory of Adriana Cavarero. Finally, Judith Butler's theory of performativity will further illuminate the acquisition of a hybrid identity through cultural and biological elements.

La hija del Ganges (2003) de la escritora india-catalana Asha Miró es un texto autobiográfico que refleja las inquietudes típicas de las historias de adopción : el trauma del abandono, la pérdida de la familia de origen, la necesidad de entender las circunstancias de su nacimiento y, sobre todo, de aclarar los motivos que llevaron a sus padres biológicos a deshacerse de ella. La elaboración textual de su periplo vital revela la importancia del acto performativo en la escritura autobiográfica en cuanto « creation and re-creation of the self at the time of writing » (Laureiro 1). Este artículo analiza la construcción identitaria de la escritura autobiográfica a partir de la teoría de la narración de la filósofa italiana Adriana Cavarero. Asimismo la teoría de la performatividad de Judith Butler ayudará a entender la adquisición de una identidad híbrida a partir de elementos culturales y biológicos.

\footnotetext{
${ }^{1}$ University of Victoria, Canada.
} 
« Adoption narratives are generally about the work of making an origin $»^{2}$.

\section{El marketing de lo subjetivo}

La proliferación de varias formas de escritura del yo, de textos testimoniales y de corte autobiográfico, impulsada a partir de la Transición por factores políticos, adquiere conotaciones marcadamente comerciales en las siguientes décadas. A textos literarios de carácter histórico, político y social que recuperan la memoria de los silenciados, se añade una vasta gama de publicaciones que ponen al desnudo « la moda de lo subjetivo » ${ }^{3}$. Según Anna Caballé, « el arraigamiento de lo autobiográfico en nuestra sociedad implica un juego de expectativas y convenciones colectivas que afecta públicos muy distintos : desde un público intelectual, minoritario, ... hasta un público amplísimo ${ }^{4}$. Dicha tendencia, evidenciada a partir de los años ochenta, va consolidándose en los noventas y sigue incrementándose en el nuevo milenio, reflejando el auge del discurso confesional tan en boga en la cultura de masas del tercer milenio. Si en el contexto neoliberal se afirma una tecnología del yo basada en la revelación de la intimidad, la industria editorial responde al gusto por la autonarración publicando numerosos textos de no-ficción que abordan, desde un prisma autobiográfico, temas candentes dentro de la sociedad española ${ }^{5}$. Con

\footnotetext{
${ }_{2}^{2}$ Margaret HOMANS, « Adoption Narratives, Trauma, and Origins », Narrative, Vol.1, enero 2006, p. 6.

${ }^{3}$ Rafael CONTE, «Entre la ficción y el yo » Leer, n. 96, (octubre de 1998), p.38. Citado por Anna CABALLÉ en su artículo « Biografía y autobiografía: convergencias y divergencias entre ambos géneros » en El otro, el mismo: biografía y autobiografía en Europa (siglos XVII-XX) ed. J.C. DAVIS e Isabel BURDIEL BUENO, Valencia, Universitat de València, 2005, p. 56.

${ }^{4}$ Anna CABALLÉ, Narcisos de tinta. Ensayo sobre la literatura autobiográfica en lengua castellana (siglos XIX y XX), Málaga, Megazur, 1995, p. 23.

${ }^{5}$ Sobre el auge de los relatos autobiográficos, expresión del individualismo postmoderno, ver además de los citados ensayos de Anna CABALLÉ, Manuel ALBERCA, El pacto ambiguo: de la novela a la autoficción, Madrid, Biblioteca Nueva, 2007, Pepa NOVELL, La memoria sublevada. Autobiografía y reivindicación del intelectual ibérico del medio siglo, Iberoamericana Vervuert, 2009, ROMERA CASTILLO, Ed. De primera mano: sobre escritura autobiográfica en España, Madrid, Visor Libros, 2006 y Virgilio TORTOSA, Escrituras ensimismadas. La autobiografía literaria en la democracia española. Alicante, Universidad de Alicante, 2001. El reciente artículo de María Pilar SAIZ CERREDA, «Identidad y representación en el discurso autobiográfico », RILCE 28.1 (2012), pp. 8-16, destaca « la pervivencia diacrónica del discurso autobiográfico » que « goza de tanta vitalidad en nuestro tiempo », p. 10. Sobre las estrategias de marketing del sector editorial en la España democrática, ver Santos ALONSO, La novela española en el fin del siglo 1975-2001, Madrid, Marenostrum, 2003.
} 
la creciente comercialización de productos editoriales de consumo, se crean nuevos géneros híbridos, destinados al gran público, en los que se evidencia « un claro intento de identificación entre las protagonistas y las lectoras ${ }^{6}$. Según Santos Alonso, la presencia de escenarios y situaciones existenciales semejantes a las vividas por los lectores resulta ser un elemento clave del éxito editorial de ciertos filones narrativos.

Dentro de este marco se sitúa la publicación de La hija del Ganges ${ }^{7}$, de la escritora indiacatalana Asha Miró cuyo relato llega a los estantes de las librerías en 2003, cuando España se convierte « en el segundo país del mundo en número de adopciones transnacionales por habitante y por menores nacidos vivos $»^{8}$. Escrita en catalán y traducida al castellano elabora, desde una perspectiva conciliadora y esperanzadora, el proceso de autoconocimiento de la autora, adoptada por una familia catalana a la edad de casi siete años. A través de una narración retrospectiva que da fe del viaje al país natal emprendido en 1995, presenta un testimonio favorable a las adopciones internacionales y se convierte en un éxito de ventas tanto a nivel nacional como internacional.

\section{Adopciones internacionales en el contexto español}

Las profundas transformaciones acontecidas en la sociedad española a partir de la Transición se reflejan en la composición y estructura de los núcleos familiares que, a partir de la década de los ochenta, con la legalización del divorcio y la despenalización de los anticonceptivos, se abren a nuevos modelos parentales. Las nuevas familias españolas se configuran a partir de una democratización de las funciones parentales y de las relaciones con los hijos que « ya no son un destino sino una elección y esto los hace más valiosos a los ojos de sus padres » ${ }^{9}$. Mientras consideraciones de carácter profesional y personal contribuyen a cuestionar la posibilidad de tener descendencia y de retrasar la edad de la maternidad, en 1995 España alcanza la tasa de fecundidad más baja de su historia, $1.17^{10}$. A partir de los años inmediatamente posteriores a la muerte

\footnotetext{
${ }^{6}$ S. ALONSO, La novela española en el fin del siglo 1975-2001, op. cit., p. 182.

${ }^{7}$ Asha MIRÓ, La hija del Ganges, trad. Gemma SARDÀ, New York, Atria Books, 2006. Todas la citas provienen de la edición norteamericana que reúne los dos libros, La hija del Ganges y Las dos caras de la luna.

${ }^{8}$ Diana MARRE, «Los silencios de la adopción en España», Revista de Antropología Social, 2009, 18, p. 106.

${ }^{9}$ Inés ALBERDI, La nueva familia española, Madrid, Taurus, 1999, p. 18.

${ }^{10}$ Datos del INE, Instituto Nacional de Estadística, 24 de junio de 2014.

http://www.ine.es/prensa/np851.pdf
} 
de Franco, se asiste a un fuerte descenso de la natalidad y, desde la mitad de los años noventa, se incrementa exponencialmente el número de adopciones internacionales. Si bien dicho fenómeno es común a la mayoría de los países occidentales, España lidera los países europeos en número de adopciones internacionales. Según indica la antropóloga Diana Marre : «En el caso de España, las adopciones internacionales se cuadruplicaron en los seis años que median entre 1997, año en que se recogieron las primeras estadísticas sobre adopciones internacionales, y 2003 y se adoptaron 18.501 menores $»^{11}$. Entre las comunidades autónomas es Cataluña la que recibe el mayor número de niños procedentes de otros países, sobre todo de China y Rusia ${ }^{12}$, lo cual ocasiona un intenso debate sobre las prácticas adoptivas y sus problemáticas.

Debido al boom de las adopciones internacionales, la industria editorial, tan atenta a la creación de productos comerciales, responde con una serie de textos que ponen el foco en la experiencia de los niños y de los futuros padres. Mientras psicólogos y educadores responden a las necesidades emocionales de los adoptados con libros dedicados a narrar las historias de niños procedentes de países como China, Rusia y Etiopía, Asha Miró proporciona a los padres la perspectiva adulta de la experiencia de la adopción transracial ${ }^{13}$. Siguiendo las pautas de la narrativa de viaje y de adopción, relata las etapas más significativas de su personal pasaje a India, emprendido en agosto de 1995, cuando se unió a un grupo de cooperantes españoles para participar en un campo de trabajo en las dos ciudades en las que se crió hasta la edad de casi siete años. A través de una narración retrospectiva, que recurre al presente narrativo para crear el efecto de simultaneidad, La hija del Ganges entreteje recuerdos del viaje con fragmentos del diario materno. Tomando como punto de partida la mañana del vuelo Barcelona-Bombay, explica las motivaciones del retorno, el rol del azar al ponerla en contacto con una ONG, su intención de emprender una labor humanitaria y su objetivo de investigar su pasado. En los doce capítulos que

\footnotetext{
${ }^{11}$ D. MARRE, « Sobre la adopción y otras formas de construir familias : a modo de introducción », La adopción y el acogimiento. Presente y perspectivas, Barcelona, Edicions de la Universitat de Barcelona, 2004, p. 25.

${ }^{12}$ Sobre el número y la procedencia de los niños adoptados en España, ver los artículos de Peter SELMAN, «The Movement of Children for International Adoption : Development and Trends in Receiving States and States of Origin, 1998-2004 » y D. MARRE, «'We Do Not Have Immigrant Children at This School, We Just Have Children Adopted from Abroad' : Flexible Understandings of Children's » in D. MARRE y Laura BRIGGS, International Adpotion. Global Inequalities and the Ciruculation of Children, New York and London, New York P, 2009.

${ }^{13}$ Sobre la narrativa de adopción destinada a un público infantil, ver « Adopción, nueva protagonista estrella de la literatura infantil », El mundo, 20 de mayo de 2005,

http://www.elmundo.es/elmundo/2005/05/20/cultura/1116614588.html.
} 
componen esta « historia de una adopción » se reconstruye un conmovedor itinerario físico e interior que evidencia el proceso de maduración y transformación de la autora a contacto con su país de origen.

Con un título poético y orientalizante, La hija del Ganges afronta las problemáticas de las adopciones internacionales desde una perspectiva personal y conciliadora, ofreciendo a los futuros padres valiosos consejos, avalados por su experiencia. Según indica en el capítulo final : « con el relato de mi caso trato de que entiendan que la adopción de los niños ya mayores no es un problema insalvable $»^{14}$. Mientras que el mercado editorial suele proponer sobre todo el punto de vista de los expertos o de las madres adoptivas, el testimonio de Miró tiene el valor añadido de incluir las dos perspectivas, demostrando que «narrative plays a crucial role in these ongoing processes of identity renegotiation $»^{15}$. En el complejo proceso de creación de la identidad de la autora, el acto de escribir contribuye a la construcción de una máscara textual muy fácilmente comercializable para un público deseoso de recibir un relato con final feliz que celebra el triunfo del amor sobre los lazos de sangre.

Ya que, en palabras de Anna Caballé, « toda autobiografía nace da la voluntad de dar un sentido a la propia vida, de trazar unas líneas de fuerza que retrospectivamente doten de coherencia a la propia existencia o al menos a parte de ella $»^{16}$, la autora reelabora la intensa experiencia vivida en India con una doble finalidad, personal y social. Por un lado, la reelaboración de la experiencia vivida en la India responde a una necesidad psicológica : «necesitaba explicarme »; por otro se presenta como una labor humanitaria : «me sentí obligada a explicar mi historia » de la que subraya el «final feliz $»^{17}$. Si en la elaboración de un texto autobiográfico se asiste a la «creation and re-creation of the self at the time of writing ${ }^{18}$, en el caso de un texto escrito con una finalidad específica, el proceso de autoescritura está vinculado a la presentación de una historia ejemplarizante que celebra el 'happy ending'.

\footnotetext{
${ }^{14}$ A. MIRÓ, La hija del Ganges, op. cit., p. 136.

${ }^{15}$ Macarena GARCÍA GONZÁLEZ y Elisabeth WESSELING, «The Stories We Adopt By: Tracing the 'Red Thread' in Contemporary Adoption Narratives », The Lion and the Unicorn, Vol. 37, n. 3. Sept. 2013, p. 258.

${ }^{16}$ A. CABALLÉ, Narcisos de tinta. Ensayo sobre la literatura autobiográfica en lengua castellana (siglos XIX y $\mathrm{XX),} \mathrm{op.} \mathrm{cit.,} \mathrm{pp.} \mathrm{53-54.}$

${ }_{17}$ A. MIRÓ, La hija del Ganges, op. cit., pp. 134-35.

${ }^{18}$ Angel LOUREIRO, The Ethics of Autobiography, Replacing the Subject in Modern Spain, Nashville, Vanderbilt UP, 2000, p. 1.
} 


\section{Adopción y autonarración}

Demostrando un profundo conocimiento de las problemáticas asociadas a las adopciones transraciales, Asha Miró, nacida en India en 1967 y adoptada tras su larga insistencia en 1974, cuando este tipo de prácticas eran todavía poco frecuentes, ofrece su testimonio personal con el objetivo explícito « de poner mi experiencia a disposición de aquellas personas a las que les pueda ser de utilidad $»^{19}$. En sus páginas, obviando los aspectos más dramáticos, afronta con naturalidad y candor temas espinosos como la relación con la familia biológica y la cultura de origen, concluyendo que gracias al amor de la familia adoptiva «todo saldrá bien $»^{20}$. A diferencia de otras narrativas de adopción en las que prevalece un tono trágico y sombrío, caracterizado por el rencor y la recriminación, como en el caso de numerosos testimonios escritos en los Estados Unidos $^{21}$, La hija del Ganges subraya los vínculos afectivos que la unen a su hermana menor, también nacida en India, y a sus padres, que supieron proporcionarle una infancia feliz, rodeada de atención, afecto y ternura.

Si bien en la literatura occidental abundan las historias protagonizadas por huérfanos que se enfrentan a las adversidades de la vida, en el texto de Miró no tienen cabida los tormentos interiores de su protagonista que, en la transposición autobiográfica, aparece como un personaje sin fisuras, con escaso espesor psicológico. En la economía del relato, las inquietudes, el sufrimiento, el dolor por el abandono quedan relegados a los márgenes de un relato contenido dentro de un marco de optimismo. Orientado a disipar las dudas de los futuros padres, pinta un cuadro muy alentador de la trayectoria vital de Miró. Por eso, desde el primer capítulo, subraya el «afecto de unos padres que nos acogieron y nos han crecido como hijas suyas ${ }^{22}$, explicando las técnicas empleadas para crear vínculos afectivos profundos y duraderos.

\footnotetext{
${ }^{19}$ A. MIRÓ, La hija del Ganges, op. cit., pp. 137-138.

${ }^{20}$ Ibid., p. 137.

${ }^{21}$ Sobre las problemáticas de las adopciones internacionales y las narrativas de adopción ver Barbara YNGVESSON, « Going 'Home'. Adoption, Loss of Bearings, and the Mythology of Roots », in Social Text, 21.1, 2003 ; Outsiders within. Writing on Transracial Adoption, Eds. Jane JEON TRENKA, y Sun Yung SHIN, Cambridge, MA, South End Press, 2006 ; Their Own Voices. Transracial Adoptees Tell Their Stories. Eds. Rita J. SIMON y Rhonda M. ROORDA, New York, Columbia UP, 2000 ; Margaret HOMANS, « Adoption Narratives, Trauma, and Origin »; Diana MARRE, «Los silencios de la adopción en España », in Revista de Antropología Social, 2009, 18, pp. 97-126.

${ }^{22}$ A. MIRÓ, La hija del Ganges, op. cit. p. 5.
} 
Mientras que en las adopciones internacionales no es infrecuente una actitud despectiva hacia el país de origen «that hinders more responsible and respectful transnational adoptions... based on the beliefs that orphaned females from Asia are like abandoned rag dolls in need of rescuing from imaginary backgrounds consisting of only abject poverty and savagery ${ }^{23}$, en la experiencia de Asha Miró prevalece el respeto y el reconocimiento de la cultura de origen de la que se subraya « la belleza de sus paisajes y sus gentes o la pobreza en la que se ven inmersos ${ }^{24}$. En una época en la que las adopciones internacionales eran una excepción, el matrimonio Miró supo reconocer el rol de los padres biológicos de los que siempre hablaron con mucha naturalidad, como se evidencia en el testimonio materno que deja constancia de sus sentimientos al construir lazos de amor con sus hijas. La franqueza con la que « en casa siempre hemos hablado sobre mi país, la tierra que me vio nacer $»^{25}$ contribuyó a crear una actitud positiva hacia la cultura de origen y sus tradiciones. Según recuerda, « las sesiones en el sofá eran la ocasión ideal para hablar de la adopción. Y resultaba sencillo, una faceta más de nuestra vida ${ }^{26}$. Durante aquellos momentos de reflexión, que ayudaron a superar el trauma del abandono y de la separación del país de origen, se reafirmaba el propósito de volver algún día a India. Si bien este proyecto nunca se concretizó, a la edad de 26 años Asha sintió la imperiosa necesidad de enfrentarse a su pasado.

El retorno a la tierra natal, a veinte años de distancia de su adopción, responde no solo a su deseo de reencontrarse con su tierra de origen, sino también a la intención de aportar algo de lo que ha recibido en su país de acogida. Consciente de sus privilegios, tras trabajar varios años como profesora de música en Barcelona, decide volver a India para ayudar a los más necesitados, desarrollando un programa de ayuda en una escuela para niños pobres y en un centro para mujeres víctimas de violencia en Bombay y luego en la construcción de acequias en una zona rural cercana a Nasik : « tenía que volver con las manos llenas, porque en mi segunda vida lo había recibido todo : una familia, unos amigos, una educación ; en definitiva una vida libre $»^{27}$.

Junto a un grupo de cooperantes españoles entra en contacto con aspectos muy dramáticos de la sociedad india : la pobreza infantil, la violencia de género, la prostitución infantil, los inmen-

\footnotetext{
${ }^{23}$ Indigo WILLIAMS WILLING, « From Orphans China Dolls to Long-Distance Daughters : A Call for Solidarity Across Borders » in Defending our Dreams : Global Feminist Voices for a New Generation. Ed. Shamilah WILSON, Anasuya SENGUPTA, and Kristy EVANS, London, Zed Books, 2005, p. 97.

${ }^{24}$ A. MIRÓ, La hija del Ganges, op. cit., pp. 7-8.

${ }^{25}$ Ibid., p. 7.

${ }^{26}$ Ibid., p. 8.

${ }^{27}$ Ibid., p. 9.
} 
sos contrastes de un país lleno de contradicciones. Al enfrentarse a las difíciles condiciones de vida en Bombay, no puede evitar preguntarse cómo habría sido su vida si se hubiera quedado allí, en aquel país que le resulta tan desconcertante y al que no logra adaptarse.

\section{En busca de los orígenes}

Como suele ocurrir en el proceso de autonarración de las historias de vida de personas adoptadas en un contexto transnacional y transracial, el relato de Miró está caracterizado por la necesidad de desvelar las incógnitas de su pasado, su familia biológica y las circunstancias en las que se verificó su nacimiento y su abandono.

«Quiero saber quiénes fueron mis padres biológicos, por qué me abandonaron, por qué no me quisieron, en qué situación se encontraban para que les supusiera tal estorbo como para deshacerse de mí ${ }^{28}$.

El dolor del abandono le lleva a « intentar resolver un gran número de interrogantes ${ }^{29}$ para poder finalmente reconciliarse con su pasado y encontrar « la paz interior $»^{30}$.

Al indagar en sus raíces culturales y étnicas, tras dos décadas de aculturación en su patria adoptiva, Miró refleja las inquietudes típicas de las llamadas « return narratives ». En dichos testimonios se asiste al intento de renegociar la identidad individual a partir de una investigación del pasado. La herida del abandono inicial, el misterio del origen y el consecuente desarraigo, ínsito en la experiencia de la adopción transnacional, se une a preocupaciones de carácter racial, étnico y nacional. En palabras de Margaret Homans, « life stories of adopted people have complex narrative lines, since to the already difficulty of any human effort to know and fix one's origin is often added the extra difficulty of lack of information about birth parents, date, place» ${ }^{31}$. A estos interrogantes se añade la ilusión de poder recobrar la llamada « birth culture », es decir, la cultura de origen, cultura que, a pesar de la distancia tanto geográfica como temporal, es considerada esencial al fin de forjar la identidad individual. Ya que «western cultures tend to equate biological origins with identity $»^{32}$, en las narrativas de adopción abundan los relatos de viajes a la tierra de origen.

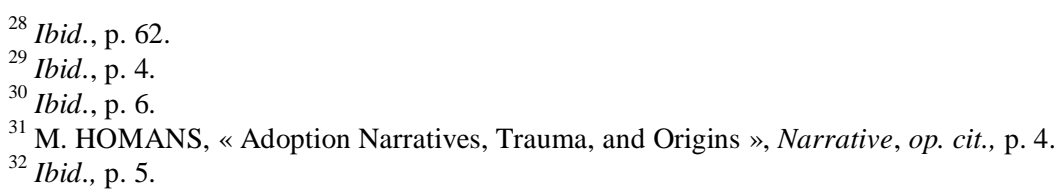


El viaje al país natal es acompañado por un poderoso mito, el de las raíces y por la idea que el reencuentro con la tierra propiciará una epifanía, una revelación que aportará datos esenciales para la construcción identitaria de su protagonista. Según la antropóloga Barbara Yngvesson, en dichos relatos se evidencia el convencimiento que « identity is associated with a root or ground of belonging that is inside the child as 'blood' ${ }^{33}$. Por lo tanto, a pesar del distanciamiento geográfico, cultural, lingüístico y racial, prevalece la idea que la fragmentación del yo-dividido a partir de líneas étnicas, familiares y socioculturales-podrá resolverse.

En contacto con aquel país multiétnico, multicultural y multilingüístico en el que vino al mundo, Miró se enfrenta al reto de entender su propia identidad a partir de la herencia genética, inscrita en sus rasgos somáticos: el color de la piel, sus facciones, la textura del pelo que evidencian su alteridad en el contexto catalán y que ella misma considera marcas incontrovertibles de su pertenencia a la sociedad india. Escribiendo desde la perspectiva de una persona completamente identificada culturalmente con su país de adopción, es decir Cataluña, la autora construye un espacio narrativo híbrido que, a través de una relación dialógica, cuestiona lo que Yngvesson denomina « exclusive belongings », es decir la noción que una persona pertenece exclusivamente a una cultura, a un país. De la estancia en Bombay, ciudad en la que residió de los tres casi hasta los siete años, el contacto con la vida cotidiana, la convivencia con una familia india, la labor de voluntariado en una escuela para niños trabajadores y con mujeres víctimas de violencia de género toma consciencia de los profundos problemas sociales de India. De allí que, consciente de sus privilegios, se interrogue sobre su posición dentro de una sociedad tan estratificada y compleja como la india.

Si al salir de Barcelona albergaba la esperanza de recobrar el idioma aprendido de niña y reintegrarse en la sociedad en la que se había criado, al confrontarse con sus connacionales, tiene que asumir que los veinte años transcurridos en España han eliminado la herencia lingüística y cultural adquirida durante la infancia. Mientras trata de superar el desconcierto que le causa haber olvidado su lengua materna, el maratí y no reconocer el sabor de las comidas, se reconforta con la lectura del diario de la madre adoptiva, que deja constancia de las dificultades a las que se enfrentó de pequeña al llegar a España: al aprender el catalán, aceptar los sabores de la comida española, acostumbrarse a un nuevo estilo de vida, a una nueva familia y a un nuevo sistema escolar. Aunque al principio se encuentra « desanimada » porque, según indica, « me cuesta

\footnotetext{
${ }^{33}$ B. YNGVESSON, « Going 'Home' Adoption, Loss of Bearings, and the Mythology of Roots », op. cit., p. 8.
} 
adaptarme $»^{34}$, la voz materna la acompaña, a través del diario, en esta segunda aventura y la anima a no darse por vencida.

No obstante los obstáculos encontrados en su intento de reintegrarse en la sociedad india y los graves problemas médicos padecidos, Miró se esfuerza por mantener un tono optimista. El relato memorialístico del reencuentro con las monjas que la criaron en los orfanatos de Bombay y Nasik y sus intentos por descubrir la identidad de sus padres y el dolor de aprender las circunstancias en las que fue recogida por las religiosas se traducen en un texto que celebra su multiculturalidad. Tanto en La hija del Ganges como en su segundo libro, Las dos caras de la luna, en el que se reescribe la autobiografía de la autora a la luz de las revelaciones de sus familiares biológicos, prevalece el deseo de forjar una identidad que es « informative about contemporary constructions of transnational Spanish identity ${ }^{35}$.

Debido al matiz ideológico de estos relatos, al analizarlos se tendrá en cuenta que « autobiography might be best aprehended not as a re-production of a life, but as an act that is at once discursive and intertextual, rhetorical, ethical, and political $»^{36}$. Asimismo se considerará la función de la performatividad teorizada por Judith Butler en el proceso de adquisición de una identidad transracial. A la luz de la teoría de la narración de Adriana Cavarero se examinará el rol del interlocutor en la construcción identitaria.

\section{Performatividad e identidad}

Mientras camina por las calles de Bombay, buscando en los rostros de sus compatriotas rasgos familiares, aprovecha las interacciones con la gente para profundizar sobre su identidad. La reacción de sus compatriotas, con los que cree poder identificarse, la desconcierta, ya que, a pesar de su herencia genética, percibe «infinidad de ojos que se clavan en mí », de personas que la «miran perplejos ${ }^{37}$. Aunque en España se había acostumbrado a ser considerada diferente, no estaba preparada para recibir un tratamiento parecido en India. La curiosidad de la gente y un conocimiento elemental de la realidad social india la inducen a indagar su lugar en el sistema de castas que, a pesar de haber sido abolido, sigue siendo un elemento fundamental. Por esta razón

\footnotetext{
${ }^{34}$ A. MIRÓ, La hija del Ganges, op. cit., p. 23.

${ }^{35}$ Ryan PROUT, «Cradling the Nation : Asha Miró's Autoethnographies, Discourses of International Adoption, and the Construction of Spanishness », in Bulletin of Spanish Cultural Studies, LXXXVI, 4, 2009, p. 500.

${ }^{36}$ A. MIRÓ, La hija del Ganges, op. cit., p. 4.

${ }^{37}$ Ibid., pp. 97-98.
} 
se anima a preguntar a un grupo de mujeres con las que colabora a qué casta pertenece. Su pregunta suscita la hilaridad de sus interlocutoras que, según explican, a pesar de su aspecto físico, la consideran extranjera.

Tienes la piel oscura, eso sí, y los ojos y el pelo muy negros, tienes la nariz y la boca como nosotras, pero tus rasgos se han occidentalizado. Sólo tenemos en común el aspecto físico, y aún. No caminas como una india, no miras como una india, no gesticulas como una india. Nosotros te vemos como una europea más ; por lo tanto no debes preocuparte por descubrir adónde pertene$\operatorname{ces}^{38}$.

En sus palabras se evidencia el aspecto performativo de la identidad ya que se puede concluir que no solo el género, sino también la etnicidad se forjan a partir de « un proceso activo de apropiación, interpretación y reinterpretación de las posibilidades culturales » ${ }^{39}$.

Partiendo de la formulación de Simon de Beauvoir que «sugiere que el género es un aspecto de la identidad que se adquiere gradualmente », Judith Butler cuestiona la construcción de la identidad sexual preguntando : «How and why does the construction of gender take place ? ${ }^{40}$. A partir de allí postula que «the gendered body is performative ${ }^{41}$. En palabras de María Luisa Feminias, « el género no solo es una construcción cultural impuesta, sino, además, un proceso de autocostrucción de la identidad », en la que cobra particular importancia « la adopción de un cierto estilo corporal, de un cierto significado asumido o encarnado positivamente $»^{42}$.

Aplicando esta teorización al aspecto étnico, podemos postular que la identidad nacional aparece como fruto de unas prácticas performativas abiertas a multiples interpretaciones. Si en España los rasgos somáticos de Asha son sinónimos de extranjería, en India es el lenguaje corporal lo que la diferencia. En el contexto del país de adopción se evidencia el aspecto racial, mientras que en India las características biológicas no son suficientes para ser considerada autóctona. Vestir la prenda habitual de las mujeres indias, el salwaar kameez, no la ayuda a reintegrarse en la sociedad de origen. Debido a su gestualidad, el aspecto performativo de su identidad la identifica como occidental. A partir de esta constatación, Miró se enfrenta al reto de asumir que su cuerpo, a pesar de la herencia genética, se ha transformado en un cuerpo híbrido abierto a interpretaciones culturales distintas y a valorar y celebrar su unicidad.

\footnotetext{
${ }^{38}$ Ibid., p. 99.

${ }^{39}$ María Luisa FEMENIAS, Judith Butler, Madrid, Ediciones del Orto, Biblioteca de Mujeres, 2003, pp. 64-65.

${ }^{40}$ Judith BUTLER, Gender Trouble. New York and London, Routledge, 1999, p. 11.

${ }^{41}$ M. L. FEMENIAS, Judith Butler, op. cit., p. 173.

${ }^{42}$ Ibid., p. 22.
} 


\section{Identidad y narración}

La necesidad de escuchar el relato de su propia existencia y de conocer las causas de su abandono mueve a la autora a volver al inmenso país en el que vio la luz para aclarar el enigma de sus raíces. Debido a la labilidad de la memoria y a su corta edad al llegar a España, Asha no puede estar segura de la veracidad de sus recuerdos, por eso ansía volver a visitar el orfanato Regina Pacis y reencontrarse con la madre Adelina, una monja puertorriqueña que la ayudó a coronar su sueño de tener padres. Convencida que esta monja pueda revelar el misterio de su pasado, en dos emotivos encuentros lleva a cabo una tarea investigadora para desvelar las incógnitas de su origen. Con afecto, la madre Adelina rememora los años de su infancia en el orfanato, es pródiga en anécdotas, pero se niega a revelar las circunstancias de su nacimiento : « no debe importarte si eres hija de ricos o pobres, las aguas sagradas de India te han dado la vida y debes pensar únicamente en vivir el regalo de Dios con dignidad, ayudando al prójimo, haciendo el bien ${ }^{43}$. Frente a sus reiteradas preguntas, la anciana religiosa propone una solución poética al enigma de su proveniencia, afirmando : «Asha, eres hija del Ganges ${ }^{44}$. Esta idea, en principio rechazada, sin embargo se refleja en el título del libro, demostrando que al final de su búsqueda, la autora supera la visión esencialista del origen y elige una filiación etnográfica más que biológica.

Al conferir a las aguas del río sagrado la función del líquido amniótico, la monja apela a la cultura local al sugerir una filiación simbólica y cultural más que biológica. Ya que en sánscrito la palabra río es femenina, la monja alude a la divinidad de sus aguas, que, como la diosa Ganga, conllevan un matiz de inmortalidad y procedencia divina ${ }^{45}$. En sus palabras se subraya la pertenencia a una cultura milenaria en la que la divinidad femenina Ganga es venerada por sus «generative powers : giving birth, restoring life, conferring immortality ${ }^{46}$. Dicha explicación no pone fin a las pesquisas de la autora que, a pesar del efecto debilitante de la malaria, emprende un largo viaje hacia Nasik para volver al convento en el que se crió hasta la edad de tres años.

\footnotetext{
${ }^{43}$ A. MIRÓ, La hija del Ganges, op. cit., pp. 62-63.

${ }^{44}$ Ibid., p. 63.

${ }^{45}$ Agradezco a Adam Martin y a Sikata Banerjee la generosidad con la que compartieron su conocimiento de la cultura de India.

${ }^{46}$ Steven DARIAN, The Ganges in Myth and History, Honolulu, The University Press of Hawaii, 1978, p. 31.
} 


\section{En busca de su relato}

Debido a la imposibilidad de recibir el relato de su existencia, Miró ansía volver a la que cree ser su ciudad natal, Nasik. Allí se evidencia como, según la teorización de Adriana Cavarero, la elaboración textual de la autobiografía, en cuanto graphos que plasma la unicidad del bios, precisa de un proceso de autoconocimiento en el que es esencial el relato ajeno. Según la filósofa italiana es en la relación dialógica donde se construye la identidad ya que «l'identità del sé, cristallizzata nella storia, è completamente costruita dalle relazioni del suo apparire agli altri nel mondo $»^{47}$. En una concepción relacional de la identidad, tanto el relato ajeno, como su perpetración a través de figuras que puedan transmitirlo, resultan cruciales en la articulación del relato personal, en cuanto « il significato dell'identità è sempre affidato al racconto altrui della propria storia di vita $»^{48}$. De ahí que en las narrativas de adopción prevalezca la búsqueda de un interlocutor privilegiado capaz de otorgar el relato de la escena originaria, que en la imaginación del adoptado puede sanar la herida causada por el abandono inicial.

Siguiendo las pautas narrativas del buildungsroman, la protagonista, superada una debilitante enfermedad que pone a prueba su capacidad de restistencia, reune las fuerzas necesarias para emprender el viaje al que considera su lugar de nacimiento : «Nasik, la cuna de mis primeros balbuceos, es una etapa ineludible en este aprendizaje, allí están aquellas piezas del rompecabezas que todavía me faltan ${ }^{49}$. En el convento donde transcurrieron los primeros tres años de su existencia, otra religiosa, la madre Nirmala, accede a contarle su historia personal : « Sin que se lo tenga que pedir, sabe qué he venido a buscar. Sabe que me dolerá y por eso lo envuelve bajo la apariencia de un cuento $»^{50}$.

El progresivo desvelamiento del pasado de la autora parece destinado a resolverse en la escena de la anagnórisis, en la que, según las normas aristotélicas, se pasa del desconocimiento al conocimiento. Sin embrago una elipsis elide este momento crucial, en el que culmina el itinerario de autoconocimiento de la narradora. Dicha omisión podría explicarse a partir de la teorización de Mieke Bal, según el cual : «El acontecimiento sobre el cual nada se ha dicho puede ser tan doloroso que esa sea precisamente la razón de que se elida. O el acontecimiento es tan difícil de ex-

\footnotetext{
${ }^{47}$ Adriana CAVARERO, Tu che mi guardi, tu che mi racconti. Filosofia della narrazione, Milano, Feltrinelli, 1997, p. 51.

${ }^{48}$ Ibid., p. 31.

${ }^{49}$ A. MIRÓ, La hija del Ganges, op. cit., p. 115.

${ }^{50}$ Ibid., p. 125.
} 
presar verbalmente, que es preferible mantener un total silencio sobre él ${ }^{51}$. En este momento culminante de la narración se asiste a un cambio de focalización y de estilo. La pretensión de veracidad con la que la narradora protagonista envuelve el relato deja paso a una versión fabulada de las revelaciones de la religiosa. Mientras en el resto del texto el uso del presente narrativo crea un efecto de simultaneidad que resalta su factualidad, el enigma de su pasado se traduce en un relato fabulado de tono erotizante en el pretérito.

En la elaboración textual de su historia de vida, la narradora hace suyo el relato recibido, suplantando la voz de su interlocutora. Con un lenguaje sensual vincula su nacimiento al despertar de la naturaleza tras las lluvias monzónicas, estableciendo una correlación entre la morfología y tonalidades cromáticas de la tierra y las mujeres que la habitan, cuyos « vientres morenos, del mismo color que la tierra curtida por el sol, llevaban las semillas de una nueva vida $»^{52}$. Así revela los detalles de su llegada al mundo, la muerte de la madre durante el parto y el reiterado abandono por parte del padre, un campesino pobre que, al quedarse viudo por segunda vez, «cayó en la desesperación y no se vio con fuerzas de criarme ${ }^{53}$. Asumido el dolor de un triple abandono en las calles de la ciudad sagrada de Nasik, la narradora recalca su deseo de construir una imagen sólida de su pasado, corroborada por detalles irrefutables como la partida de bautizo conservada en la cercana iglesia de Santa Ana. Allí encuentra « las últimas piezas del rompecabezas, las que le darán solidez para que no se desmonte nunca más $»^{54}$. Gracias a los datos anagráficos contenidos en el registro parroquial, la narradora descubre la identidad de los que cree ser sus padres biológicos, Radhu Kashinat Ghoderao and Shebvai y da por concluida su búsqueda. Esta es la sustancia que se plasma en La hija del Ganges, libro que catapultó a su autora a la fama mediática y que está en la raíz de su segundo libro, Las dos caras de la luna, en el que el éxito de su narración la lleva a enfrentarse a otra fascinante versión de su historia.

\section{Cuestionamiento de la construcción autobiográfica}

A partir de las experiencias vividas en India, Miró compone un texto que es a la vez una narrativa de viaje y un relato autobiográfico. La construcción de un yo público en La hija del Ganges refleja algunas características que se han evidenciado en las prácticas autobiográficas de la de-

\footnotetext{
${ }^{51}$ Mieke BAL, Teoría de la narrativa (Una introducción a la narratología), Madrid, Cátedra, 1995, p. 79.

${ }^{52}$ A. MIRÓ, La hija del Ganges, op. cit., p. 126

${ }^{53}$ Ibid., p. 127.

${ }^{54}$ Ibid., p. 130.
} 
nominada modernidad líquida teorizada por Zygmunt Bauman. Frente a la fragilidad e incertidumbre postmoderna, « la autoescritura conlleva la urgencia de hacer coherente el yo cuando se mueve en la incertidumbre, insertándolo a través del texto en un momento socio-cultural que le dé sentido y sostenga su identidad $»^{55}$. A diferencia de las autobiografías postcoloniales en las que prima el aspecto fragmentado de un yo dividido según líneas raciales o nacionales, el texto de Miró intenta componer un retrato coherente, sin fisuras, en el que los interrogantes identitarios encuentran respuestas irrefutables. Por lo tanto, tras el encuentro con la hermana Nirmala, afirma con satisfacción : «La niebla que rodeaba mi origen se ha desvanecido. Estoy pisando la ciudad donde nací, sé cómo fui a parar al convento y después a Bombay para volar finalmente a Barcelona. Todos los vacíos se han llenado de palabras e imágenes concretas que expresan mi realidad $»^{56}$.

En el entramado narrativo que conforma La hija del Ganges se refleja la convicción de la autora de haber por fin desvelado el misterio de su existencia.

A nivel estilístico el empleo del presente histórico con su efecto de contemporaneidad responde a una concepción mimética del relato autobiográfico. Al elidir la perspectiva temporal, el relato resta importancia al aspecto retrospectivo de la escritura autobiográfica, aspecto que, según la famosa definición de Philippe Lejeune, constituye un elemento esencial de dicho género. En cuanto « récit retrospectif en prose qu'une personne rèelle fait de sa propre existance, lors qu'elle met l'accent sur sa vie individuelle, en particulier sur l'histoire de sa personnalité ${ }^{57}$, la autobiografía se escribe a partir de un presente desde el que se rememoran vivencias pasadas. El pacto que se establece con el lector se basa en un principio de identidad entre el autor y el yo narrante y de veracidad. En otras palabras, según el teórico francés el autor de un texto autobiográfico se compromete a contar la verdad sobre su existencia, una existencia de la que se subraya la individualidad y el desarrollo de la personalidad.

La construcción narrativa de Miró resalta la voluntad de preservar los recuerdos de los lugares en los que se crió, fijándolos en imágenes : « No paro de hacer fotos, de cada cosa, de cada rincón. Estoy tomando muchas para que todo quede grabado, porque a partir de ahora no puede haber sombras ni imagenes borrosas en mi memoria, y también para contarlo cuando regrese a Barcelona $»^{58}$. En su intento por esclarecer las circumstancias de su pasado, se apoya en referen-

\footnotetext{
${ }^{55}$ Alicia Molinero DE LA IGLESIA, « Modelos culturales y estética de la identidad », RILCE 28.1 (2012), p. 175

${ }^{56}$ A. MIRÓ, La hija del Ganges, op. cit., p. 131.

${ }^{57}$ Philippe LEJEUNE, Le pacte Autobiographique, Paris, Seul, 1975, p. 14.

${ }^{58}$ A. MIRÓ, La hija del Ganges, op. cit., p. 48.
} 
cias visuales para obviar a la posible falacia de su percepción. Asismismo traslada la convicción de poder reproducir fielmente las experiencias vividas a una escritura cuyo efecto de simultaneidad parece obviar la desfiguración de la memoria en la reconstrucción autobiográfica. En su pretensión de veracidad y factualidad, la narradora parece ignorar los efectos de los procesos rememorativos y las limitaciones de la lógica occidental para entender la realidad india. Sin embargo, cuando por fin la historia personal de Miró parece haberse aclarado y su libro se ha convertido en un superventas, al volver a India en 2003 para rodar un documental basado en $L a$ hija del Ganges se enfrenta a una realidad inesperada que le hacen cuestionar la veracidad de su relato.

\section{Las dos caras de la luna}

El retorno a India para traducir en imágenes su historia personal pone en evidencia la compleja relación entre lo vivido y lo evocado, así como la problemática mediación de la memoria. Asimismo revela la necesidad de entender las costumbres locales al fin de descifrar sus práticas culturales. Si al final de esta « historia de una adopción » la narradora afirma « el hecho de llenar vacíos, de encontrar respuestas, me ha llevado a reconocerme, a conformar una identidad mucho más sólida ${ }^{59}$, el rodaje de su historia de vida, la enfrenta a una realidad mucho más compleja y conmovedora que la obliga a reescribir su biografía. Al volver al convento Regina Pacis de Bombay aprende con desconcierto que las monjas consideran que La hija del Ganges « estaba repleto de errores ${ }^{60}$. Según las religiosas, Miró no solo se había equivocado al describir las condiciones de vida en el orfanato, sino que toda la historia de su nacimiento y del consecuente abandono no corresponde a verdad.

Si en el capítulo inicial de La hija del Ganges afirmaba : « sé que mi primer llanto fue en Nasik, en el oeste del país; sé que mis primeros años de vida transcurrieron en un orfanato de Bombay y poco más» ${ }^{61}$, gracias al relato de las religiosas y de un interprete local, Francis Waghmare, aprende que en realidad nació en un pequeño pueblo rural, Shaha, a unos setenta kilómetros de distancia de Nasik y que su padre nunca la abandonó. El reencuentro con dos de sus hermanas biológicas, Asha y Sakubai, contribuye a reconstruir su misterioso pasado. En con-

\footnotetext{
${ }^{59}$ Ibid., p. 133.

${ }^{60}$ A. MIRÓ, Las dos caras de la luna, en La hija del Ganges, op. cit., p. 151.

${ }^{61}$ A. MIRÓ, La hija del Ganges, op. cit., p. 4.
} 
tacto con la familia de origen, la imagen de un padre desalmado, que deja repetidamente a su recién nacida en las esquinas de la ciudad, es sustituida por un relato mucho más edificante que muestra las circunstancias adversas a las que se enfrentó tras el fallecimiento de su segunda mujer. Al quedarse viudo por segunda vez, el pobre campesino que ya tenía cinco hijos del primer matrimonio y otros tantos del segundo, pidió a Sakubai, hija de su primera mujer y prácticamente coetánea de la esposa fallecida, que se hiciera cargo de la bebé, amamantándola junto a su recién nacido. Debido a las estructuras patriarcales vigentes en las zonas rurales de India, el suegro de Sakubai la obligó a alimentar únicamente a su hijo varón. En la imposibilidad de hacerse cargo de la niña, el padre se puso en contacto con unos misioneros católicos para asegurar su supervivencia y antes de dejarla al cuidado de las monjas, intercambió su nombre, Usha, por el de la hermana mayor, Asha, para que la esperanza, ínsita en el nombre, guiara su existencia.

En su segunda visita a la iglesia de Santa Ana, la autora descubre además que el registro parroquial examinado en 1995 no sigue la lógica occidental de incluir el nombre de la madre biológica, sino el de la primera mujer del padre. El nombre de su madre, Sitabai, que murió unos pocos meses después de dar a luz a su quinta criatura, no aparece en ningún documento porque : « en aquellos años y en estos tipos de registros sólo figuraba la primera esposa del hombre, que era la mujer oficial, la que contaba $»^{62}$. La confusión originada por el documento pone en evidencia la importancia de conocer las prácticas discursivas en las que se sustentan los documentos oficiales.

El relato no aclara cómo se produjeron dichos errores. A nivel formal, como hemos visto, la fabulación de la anagnórisis puede haber contribuido a una desfiguración de los hechos. Las imprecisiones acerca de su abandono se pueden atribuir a cierta « lacune informative qu'il importe de combler afin de déterminer avec exactitude la tendance, fictionelle ou factuelle, du texte ${ }^{63}$. Resulta sin embargo difícil poder determinar el nivel de factualidad de la construcción narrativa de la escena anagnórica. El tono y el estilo empleado envuelven los hecho en un aura poética más propia de la fábula que de la escritura autobiográfica. La narradora responde a las acusaciones de las religiosas defendiendo su buena fe insistiendo que no pudo haberse inventado lo que escribió. Sin embargo la narradora no se demuestra muy interesada en aclarar las causas del error, sino en ractificarlo, para plasmarlo en una narrativa comercializable para ofrecerla como testimonio a sus lectores. La posible explotación comercial de su melodramática historia le

\footnotetext{
${ }^{62}$ A. MIRÓ, Las dos caras de la luna, op. cit., p. 213.

${ }^{63}$ Philippe VILAIN, L'Autofictión en théorie : suivi de deux entretiens avec Philippe Sollers \& Philippe Lejeune, Chatou, Les Éditions de la Transparence, 2009, p.13.
} 
otorga la posibilidad de reescribir su autobiografía a la luz de las revelaciones de los que presenciaron su nacimiento.

\section{Conclusión}

Tanto La hija del Ganges (2003) como Las dos caras de la luna (2004) dan fe del intento de reconstrucción de la identidad del yo narrado. Aunque el segundo libro, a la luz de las revelaciones de los que fueron testigos de su nacimiento, desmiente la veracidad de los hechos narrados en el primero, en ambos asistimos a un proceso de construcción textual de la identidad que confirma la tesis de Loureiro quien afirma que : «identity is created or constructed at the moment of writing ${ }^{64}$. Al forjar una identidad híbrida, fruto de la interacción de elementos culturales y biológicos, ambos textos ofrecen una fabulación del complejo proceso de búsqueda de las raíces de la autora a un público lector compuesto por «madres y padres en proceso de adopción ${ }^{65}$. A ellos y a sus hijos está destinada esta emotiva narración. Los elementos paratextuales, en particular la « Nota final dedicada a los protagonistas de esta historia ${ }^{66}$, ofrecen algunas pistas para entender el tipo de pacto autobiográfico que la autora establece al momento de dar forma narrativa a su historia. A diferencia del pacto entre autor y público teorizado por Lejeune, Miró se demuestra interesada en establecer su credibilidad con los que fueron testigos de su existencia y le otorgaron su relato. Por eso afirma : «Cualquier imprecisión que pueda detectarse en este relato es fruto del paso del tiempo, que ha ido borrando unas huellas difíciles de rastrear. He intentado reconstruirlas con todo lo que me han contado, a veces atendiendo más a unas fuentes que a otras, pero siempre con la mejor de las intenciones ${ }^{67}$.

Con esta advertencia demuestra su voluntad de decir la verdad, admitiendo que la distancia temporal pudo haber distorsionado sus impresiones y recuerdos de los hechos. Asimismo, confirma el rol fundamental de sus interlocutores, es decir los que le contaron su propia historia, en su construcción autobiográfica.

\footnotetext{
${ }^{64}$ Angel LOUREIRO, The Ethics of Autobiography. Replacing the Subject in Modern Spain, Nashville, Vanderbilt UP, 2000, p. 16.

${ }^{65}$ A. MIRÓ, La hija del Ganges, op. cit., p. 261.

${ }^{66}$ Ibid., p. 265.

${ }^{67}$ Ibidem.
} 